\title{
All open Do pacifiers increase the risk of nosocomial diarrhoea? A cohort study
}

\author{
Gabriela Cunha Schechtman Sette, ${ }^{1}$ Maria Júlia Gonçalves Mello, ${ }^{2}$ \\ Jailson Barros Correia, ${ }^{3}$ Ioram Schechtman Sette, ${ }^{1}$ Gisélia Alves Pontes da Silva, ${ }^{1}$ \\ Luciane Soares de Lima $^{1}$
}

To cite: Sette GCS, Mello MJG, Correia JB, et al. Do pacifiers increase the risk of nosocomial diarrhoea? A cohort study. BMJ Open 2012;2:e000427.

doi:10.1136/

bmjopen-2011-000427

- Prepublication history for this paper are available online. To view these files please visit the journal online (http://dx.doi.org/10.1136/ bmjopen-2011-000427).

Received 26 October 2011 Accepted 27 February 2012

This final article is available for use under the terms of the Creative Commons Attribution Non-Commercial 2.0 Licence; see http://bmjopen.bmj.com

${ }^{1}$ Universidade Federal de Pernambuco, Recife, Brazil ${ }^{2}$ Instituto de Medicina Integral Prof. Fernando Figueira, Faculdade Pernambucana de Saúde, Recife, Brazil

${ }^{3}$ Instituto de Medicina Integral Prof. Fernando Figueira, Faculdade de Ciências Médicas, Universidade de Pernambuco, Recife, Brazil

Correspondence to Dr Maria Júlia Gonçalves de Mello;

mjuliagmello@gmail.com

\section{ABSTRACT \\ Design: Prospective cohort study. \\ Setting: Teaching paediatric hospital-Instituto de Medicina Integral Prof. Fernando Figueira (IMIP), \\ Recife, Northeast Brazil.}

Participants: 378 of 536 infants admitted in paediatric wards from April to October 2009 were daily assessed during hospital stay until the first episode of nosocomial diarrhoea (ND), death or discharge. Infants with community-acquired diarrhoea, respiratory or haemodynamic instability and who stayed in hospital for $<24 \mathrm{~h}$ were excluded.

\section{Primary and secondary outcome}

measures: Incidence and risk factors for ND and rates of pacifier faecal contamination.

Results: 33 ND episodes occurred in 378 infants, with a cumulative incidence of $8.7 \%$ and density of 11.25 / 1000 patients-day. ND occurred in $8.2 \%(16 / 194)$ of pacifier users compared with $9.2 \%(17 / 184)$ in nonusers (adjusted $\mathrm{OR}=0.88,95 \% \mathrm{Cl} 0.43$ to 1.80 ). In multivariate logistic regression analysis, duration of oxygen use ( $\mathrm{OR}=1.61 ; 95 \% \mathrm{Cl} 1.18$ to 2.20$)$ and days of antimicrobial use ( $\mathrm{OR}=1.62,95 \% \mathrm{Cl} 1.34$ to 1.94$)$ were associated with higher risk of ND, whereas being breast fed $(\mathrm{OR}=0.40,95 \% \mathrm{Cl} 0.17$ to 0.93$)$ and each day of hospital stay ( $\mathrm{OR}=0.65,95 \% \mathrm{Cl} 0.53$ to 0.80 ) were protective factors. Faecal coliforms were isolated in $16 \%(27 / 169)$ of tested pacifiers, $77.8 \%$ of which had more than $100000 \mathrm{CFU} / \mathrm{ml}$. The probability of a child remaining free of an episode of diarrhoea up to the seventh day of hospitalisation in the ward was $91.2 \%$ (95\% Cl $87.7 \%$ to $94.9 \%$ ). The log-rank test showed no statistical difference between pacifier users and non-users.

Conclusions: ND is a frequent healthcare-associated infection in paediatric wards, but the use of pacifiers during the stay in hospital does not seem to affect the incidence of ND in infants in many settings where the burden of diarrhoea is still high.

\section{INTRODUCTION}

Nosocomial diarrhoea (ND) in children is associated with increased morbidity, mortality and length and cost of hospital stay. ${ }^{1}$ Low adherence to hand washing facilitates person to person spread of diarrhoea pathogens in

\section{ARTICLE SUMMARY}

Article focus

- Healthcare-associated infections in paediatric hospital.

- ND incidence.

- Influence of pacifier use and ND in hospitalised children.

Key messages

- Pacifier use is common in paediatric wards and ND is a frequent healthcare-associated infection in hospitalised infants.

- The use of pacifiers during hospital stay does not seem to affect the incidence of ND in infants in a high diarrhoea burden setting. Breast feeding reduces the incidence of ND in infants in a high diarrhoea burden setting.

Strengths and limitations of this study

- The study did not assess microbial aetiology of ND and, due to limited isolation facilities, infants admitted with community-acquired diarrhoea were not routinely segregated in this study setting.

- To our knowledge, this is the first report of a hospital-based prospective cohort designed to investigate the association of pacifier use and the risk of ND in infants.

hospital settings, but indirect transmission also plays a role. Potential sources of transmission include water, food or contaminated surfaces such as toys or bed linen, as well as bottle and pacifier teats. ${ }^{2}$ Despite controversy surrounding the recommendation of pacifier use, their use is very common in paediatric wards. ${ }^{3}$ Previous reports have investigated pacifier use and the risk of diarrhoea in community settings, ${ }^{4}$ but we could find no well-designed studies looking into pacifier use and hospital-acquired diarrhoea. This report investigates the association of pacifier use and the risk of ND in a cohort of children from Recife, Brazil.

\section{METHODS}

This was a hospital-based prospective cohort study of children aged $>28$ days and $<2$ years 
old who were admitted to the Instituto de Medicina Integral Prof. Fernando Figueira (IMIP) in Recife, Northeast Brazil. IMIP is a publically funded teaching hospital that has three paediatric wards for children $<2$ years old. Each ward has an area of $25 \mathrm{~m}^{2}$ within which nine cradles and nine chairs (for accompanying parents). In each ward, there is a sink with constantly supplied running chlorinated water, liquid soap and disposable paper towels. For the healthcare workers, disposable latex gloves are used for patient handling during procedures when there is risk of exposure to body fluids. Children admitted to hospital for causes other than diarrhoea were consecutively enrolled between April and October 2009.

Accompanying parents or guardians were asked if pacifiers were brought to hospital and children were observed daily. The use of any pacifier during the hospital stay was the main exposure measure, while the first episode of ND was the main outcome measure. Children presenting-diarrhoea after $<72 \mathrm{~h}$ or who were hospitalised for $<24 \mathrm{~h}$, those admitted for community-acquired diarrhoea and those presenting with haemodynamic or respiratory instability were excluded.

ND was defined as liquid stools for more than $12 \mathrm{~h}$, with or without fever or vomiting, and no likely non-infectious cause that was acquired after $72 \mathrm{~h}$ of admission. ${ }^{1}$

The possible factors associated with nosocomial infectious diarrhoea were as follows: socioeconomic variables (per capita income of family, mother's level of education), sex and age ( $\leq 6$ months), nutritional status (considering $\leq-2$ weight/age z-score WHO curve $2007),{ }^{5}$ low weight at birth $(<2500 \mathrm{~g})$, prematurity $(<37$ weeks gestational age), breast feeding, finger sucking habit, use of baby bottles and rotavirus vaccination status (Rotarix ® GlaxoSmithKlineBiologicals Laboratory, oral vaccine, attenuated monovalent (G1P [8], strain RIX4414)). Other exposure factors investigated during hospitalisation and before the occurrence of the outcome or discharge were use of medication (antibiotics, antiemetics, glucocorticoids, sedatives/ analgesics, H2 blockers), fasting (feeding withdrawn due to gastric residues) and use of common invasive procedures (central venous catheter, urinary catheter, gastric tube, oxygen therapy by nasal catheter). The length of stay (LOS) and the patient-days of use of medication or devices were measured up to the occurrence of firstonset episode of diarrhoea, discharge from hospital or death.

Data from the medical and nursing charts and those from direct observation were recorded in a standardised form by a research nurse and research assistant on a daily basis until discharge. Changes in exposure factors, clinical condition or diarrhoeal episodes were recorded.

A sample size calculation was performed using EpiInfo V.3.5.1. To inform power calculations, we did use local ward survey data that found that a third of the mothers of babies hospitalised in the weeks prior to study enrolment reported pacifier use. Assuming a 9\% frequency of ND in non-exposed children, 354 children would be required to detect a difference of $20 \%$ in the risk of diarrhoea, with $80 \%$ statistical power and a $5 \%$ level of significance. To allow for possible losses, 378 children were enrolled.

Data were entered in duplicate, and statistical analyses were performed using STATA V.9.1. ORs were described with $95 \%$ CIs and each variable was controlled for LOS. Use of pacifiers and variables associated with the risk of diarrhoea at a level of $\mathrm{p}<0.2$ in bivariate analysis were selected for inclusion in the multivariate model. A backward stepwise procedure was followed to obtain adjusted OR in multivariate logistical regression. The $\mathrm{R}$ software V.2.6.0 was used for survival analysis (The R Foundation for Statistical Computing).

To assess colonisation by faecal coliforms, pacifier teats were immersed in brain-heart-infusion media. Specimens were immediately taken to the hospital microbiology laboratory and plated on to MacConkey and Hektoen Enteric Agar (Himedia Laboratories, Mumbai, India). Isolates with appropriate colonial morphology were subcultured and confirmed to be oxidase-negative Gram-negative bacilli. TSI (Triple Sugar Iron Agar) and SIM (Sulfide Indole Motility) tests were used to differentiate Klebsiella spp. from other enteric bacilli according to the Clinical and Laboratory Standards Institute guidelines. ${ }^{6}$

The study was approved by IMIP's Research Ethics Committee and all parents or guardians had signed a consent form.

\section{RESULTS}

Throughout the study period, 378 of 536 infants fulfilled the eligibility criteria. Fifty-six $(10.4 \%)$ children with community-acquired diarrhoea, 90 with either respiratory or haemodynamic instability; five who stayed in hospital for $<24 \mathrm{~h}$ were excluded. There were seven losses $(1.3 \%)$ due to failure to obtain informed consent.

The cohort of 378 infants was followed for a total of 2932 patient-days. There was a predominance of male (59\%), and the median age was 4.1 months (IQR 2-9.6 months). Children came from a low socioeconomic status with median family income (monthly) per capita of U\$64.87 (IQR 32.49-93.23) and maternal schooling of 9 years (IQR 7-12 years) among those with $\mathrm{ND}$ and 8 years for those without diarrhoea (IQR 6-12 years). Fifty-five per cent $(208 / 378)$ of children were being breast fed (either exclusively or mixed) at the time of admission to hospital. The median duration of exclusive breast feeding was 2 months.

Thirty-three of the 378 infants developed ND $(8.7 \%)$ with an incidence density of 11.3 per 1.000 patient-days. Table 1 shows the distribution of infants with and without ND according to the factors reported at admission and observed during hospitalisation. Almost half of 
Table 1 Frequency distribution and bivariate analysis of the association between intrinsic and extrinsic factors and the occurrence of nosocomial diarrhoea (ND) in infants paediatric wards at IMIP, from 1 April to 31 October 2009

\begin{tabular}{|c|c|c|c|c|c|}
\hline Variables & $\begin{array}{l}\text { All infants } \\
N=378\end{array}$ & $\begin{array}{l}\text { Patients } \\
\text { with ND } \\
n=33\end{array}$ & $\begin{array}{l}\text { Patients } \\
\text { without ND } \\
n=345\end{array}$ & OR $(95 \% \mathrm{Cl})^{*}$ & p Value \\
\hline & n (\%) & n (\%) & n (\%) & & \\
\hline \multicolumn{6}{|l|}{ Intrinsic factors } \\
\hline Pacifier user in the hospital & $194(51.3)$ & $16(48.5)$ & $178(51.6)$ & $0.88(0.43$ to 1.80$)$ & 0.72 \\
\hline Bottle feeding & $281(74.3)$ & $21(64.0)$ & $260(75.4)$ & $0.57(0.27$ to 1.21$)$ & 0.15 \\
\hline Finger sucking habit & $36(9.5)$ & $3(9.0)$ & $33(9.6)$ & $0.95(0.27$ to 1.32$)$ & 0.94 \\
\hline Rotavirus vaccination & $173(45.8)$ & $16(48.5)$ & $157(45.5)$ & $0.87(0.43$ to 1.80$)$ & 0.73 \\
\hline Age $\leq 6$ months & $234(62.0)$ & $21(64.0)$ & $213(61.7)$ & 1.09 (0.52 to 2.29$)$ & 0.82 \\
\hline Sex, male & $223(59.0)$ & $21(64.0)$ & $202(58.5)$ & 1.25 (0.59 to 2.62$)$ & 0.56 \\
\hline Low weight at birth & $61(16.1)$ & $5(15.1)$ & $56(16.2)$ & 0.92 (0.34 to 2.48$)$ & 0.87 \\
\hline Prematurity & $67(17.7)$ & $6(18.2)$ & $61(17.7)$ & $1.03(0.41$ to 2.61 & 0.94 \\
\hline Breast feeding & $208(55.0)$ & $12(36.4)$ & $196(56.8)$ & $0.43(0.20$ to 0.90$)$ & 0.03 \\
\hline $\begin{array}{l}\text { Nutritional status, weight/age } \\
\text { z-score } \leq-2\end{array}$ & $56(14.8)$ & $6(18.2)$ & $50(14.5)$ & $1.3(0.50$ to 3.34$)$ & 0.59 \\
\hline \multicolumn{6}{|l|}{ Extrinsic factors } \\
\hline \multicolumn{6}{|l|}{ Use of devices or medication } \\
\hline Central venous catheter & $31(8.2)$ & $6(18.2)$ & $25(7.2)$ & 2.96 (1.06 to 8.23$)$ & 0.04 \\
\hline Peripheral venous catheter & $281(74.3)$ & $25(75.8)$ & $256(74.2)$ & 1.08 (0.47 to 2.49$)$ & 0.85 \\
\hline Gastric tube & $86(22.7)$ & $12(36.4)$ & $74(21.4)$ & $2.1(0.986$ to 4.53$)$ & 0.06 \\
\hline Oxygen therapy by nasal catheter & $48(12.7)$ & $6(18.2)$ & $42(12.2)$ & $1.59(0.62$ to 4.13$)$ & 0.34 \\
\hline Antibiotic & $264(69.8)$ & $25(75.8)$ & $239(69.3)$ & $1.38(0.60$ to 3.16$)$ & 0.44 \\
\hline Corticoids & $113(29.9)$ & $11(33.3)$ & $102(29.7)$ & 1.19 (0.55 to 2.54$)$ & 0.66 \\
\hline Gastric acid $\mathrm{H} 2$ blockers & $54(14.2)$ & $6(18.2)$ & $48(14.0)$ & 1.36 (0.53 to 3.52$)$ & 0.52 \\
\hline \multirow[t]{2}{*}{ Prolonged fasting } & 73 (19.3) & $6(18.2)$ & $67(19.4)$ & 0.91 (0.36 to 2.30$)$ & 0.84 \\
\hline & Median (IQR) & Median (IQR) & Median (IQR) & & \\
\hline LOS, patient-days $†$ & $266(4-10)$ & $6(4-10)$ & $6(4-9)$ & $1.00(0.97$ to 1.04$)$ & 0.83 \\
\hline \multicolumn{6}{|c|}{ Device utilisation, patient-days of use $†$} \\
\hline Central venous catheter & $177(0-0)$ & $0(0-0)$ & $0(0-0)$ & $1.09(0.97$ to 1.23$)$ & 0.14 \\
\hline Peripheral venous catheter & $856(0-3)$ & $2(1-3)$ & $2(0-3)$ & $0.98(0.84$ to 1.13$)$ & 0.76 \\
\hline Gastric tube & $465(0-0)$ & $0(0-2)$ & $0(0-0)$ & $1.10(0.98$ to 1.22$)$ & 0.09 \\
\hline Oxygen therapy by nasal catheter & $125(0-0)$ & $0(0-0)$ & $0(0-0)$ & $1.32(1.04$ to 1.68$)$ & 0.02 \\
\hline Antibiotic & $1449(0-6)$ & $7(1-11)$ & $2(0-6)$ & $1.49(1.28$ to 1.74$)$ & 0.00 \\
\hline Corticoids & $408(0-1)$ & $0(0-1)$ & $0(0-1)$ & $1.04(0.92$ to 1.18$)$ & 0.50 \\
\hline Gastric acid $\mathrm{H} 2$ blockers & $344(0-0)$ & $0(0-0)$ & $0(0-0)$ & $1.03(0.93$ to 1.13$)$ & 0.61 \\
\hline Prolonged fasting & $145(0-0)$ & $0(0-0)$ & $0(0-0)$ & $0.95(0.71$ to 1.28$)$ & 0.75 \\
\hline
\end{tabular}

the infants $(51.4 \%)$ enrolled at this cohort study (194/ 378) used a pacifier during their stay in hospital. The rate of pacifier use in breastfed babies was 65\% (135/ 208 ) and $35 \%$ for non-breastfed babies (59/170). Pacifiers users presented $8.2 \%$ (16/194) of hospital-acquired diarrhoea compared with $9.2 \%(17 / 184)$ at non-users (time adjusted bivariate analysis $\mathrm{OR}=0.88$, 95\% CI 0.43 to 1.80$)$. There were no differences between median LOS for pacifier users (6 days, IQR 4-10 days) and nonusers (6 days, IQR 4-9 days). Twelve (3\%) children died during follow-up, two of whom had ND.

In multivariate logistic regression analysis (table 2), risk and protective factors for nosocomial diarrhoea, controlled for LOS, were duration of oxygen by nasal catheter use $(\mathrm{OR}=1.61,95 \%$ CI 1.18 to 2.20$)$, days of antimicrobial use $(\mathrm{OR}=1.62,95 \%$ CI 1.34 to 1.94$)$, being breast fed during the hospitalisation $(\mathrm{OR}=0.40,95 \% \mathrm{CI}$
0.17 to 0.93$)$, each day on hospital stay $(\mathrm{OR}=0.65,95 \%$ CI 0.53 to 0.80$)$ and pacifier user $(\mathrm{OR}=1.03,95 \%$ CI 0.43 to 2.47 ).

The likelihood of a child remaining free of ND for each day of stay in the paediatric ward was estimated using the Kaplan-Meier method, and the curves for pacifier users and non-users were drawn (figure 1). The probability of a child remaining free of an episode of diarrhoea up to the seventh day of hospitalisation in the ward was $91.2 \%$ (95\% CI $87.7 \%$ to $94.9 \%$ ). The log-rank test showed no statistical difference between pacifier users and non-users.

One hundred and sixty-nine $(87.1 \%)$ of 194 pacifiers were available for culture, 16 belonged to the infants with diarrhoea and 153 for those without diarrhoea. Faecal coliforms were isolated in $16 \%(27 / 169)$ of samples. Among the infants with diarrhoea, in only one 
Table 2 Multivariate analysis of the risk factors for occurrence of ND in IMIP paediatric ward, from 1 April to 31 October 2009

\begin{tabular}{|c|c|c|}
\hline Variables & OR $(95 \% \mathrm{Cl})$ & p Value \\
\hline $\begin{array}{l}\text { Days of use of oxygen } \\
\text { therapy (nasal catheter) }\end{array}$ & 1.61 (1.18 to 2.20$)$ & 0.003 \\
\hline Days of use of antibiotics & 1.62 (1.34 to 1.94$)$ & 0.000 \\
\hline Breast feeding & 0.40 (0.17 to 0.93$)$ & 0.034 \\
\hline LOS in paediatric ward* & 0.65 (0.53 to 0.80$)$ & 0.000 \\
\hline Pacifier user & 1.03 (0.43 to 2.47$)$ & 0.936 \\
\hline
\end{tabular}

pacifier was isolated a coliform (6.3\%) and $16.0 \%$ within those without diarrhoea $(\mathrm{p}=0.47)$.

\section{DISCUSSION}

Despite the high costs and morbidity associated with ND, the frequent use of pacifiers by children admitted to hospital and the potential of enteropathogens colonising pacifiers, this is, to our knowledge, the first report to prospectively assess the role of pacifiers in ND. The risk of ND in children between 29 days and $<2$ years of age at IMIP paediatric wards during the 6-month study period was not different in children who were classified as pacifier users versus children who did not use a pacifier.

Most infants in our cohort were pacifier user; however, there was no statistically significant association between pacifier use and the occurrence of nosocomial diarrhoea. Described by the terms 'pacifier', and regionally in northeastern Brazil as 'comfort', the use of pacifiers seems to be indicated in order to 'pacify' or 'comfort' the restless, especially suffering ill child. ${ }^{78}$ Randomised

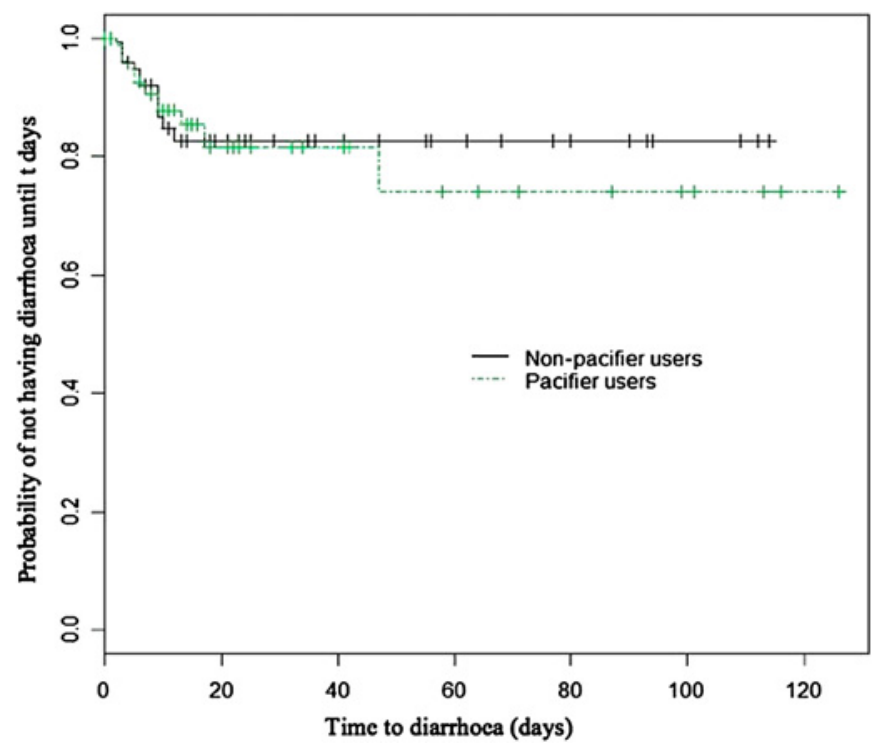

Figure 1 Stratified curve of time until occurrence of diarrhoea for the non-pacifier and pacifier users. clinical study investigated the effect of non-nutritive sucking (sucking of sterile water, sucrose or pacifier) as an analgesic during invasive procedures and has been shown that the use of a pacifier calms and modifies pain perception. $^{9}$

The lack of an association between pacifier use and diarrhoea has been previously reported in a community setting. Tomasi $e t a t^{t}$ performed a cross-sectional study in poor neighbourhoods of Pelotas, Brazil, and found no association between pacifier use and communityacquired diarrhoea, even though faecal coliforms were present in half of the tested pacifiers. The authors suggested that, in the highly contaminated environments where families from low socioeconomic backgrounds live, the added risk of using pacifiers would not significantly change the incidence of diarrhoea. This may also be true for the baby cradle environment in a busy and crowded hospital ward, where contamination vectors are likely to include the hands of professionals and associates, as well as food, water, utensils and hospital supplies. ${ }^{2} 4$

The protective effect of breast feeding in ND, observed in this study $(\mathrm{OR}=0.40,95 \%$ CI 0.17 to $0.93, \mathrm{p}=0.03)$, corroborates the evidence from the literature on the protection of breast feeding in prevention of infections especially diarrhoeal diseases in the community. ${ }^{10-12}$ The ND was an adverse event that occurred in the first days of hospitalisation.

Arguably, the relative importance of contaminated pacifiers could be different in settings with lower incidences of nosocomial gastrointestinal infection. Accompanying persons stay with their children for most of the time and it is not culturally acceptable to offer a child someone else's pacifier, we deem as small the risk of an occasional unrecorded exposure. However, circumstances similar to the present study site are often found in many settings in low- and middle-income countries, where the burden of diarrhoea is highest. The present study suggests that, in isolation, measures to restrict the use of pacifiers in hospital are unlikely to affect the incidence of ND in such settings. Health professionals should thus focus on known effective measures, such as hand washing, and look for factors other than the use of pacifiers in their efforts to prevent spread of diarrhoeal pathogens in the hospital. ${ }^{2} 1314$

While the evidence-based benefits and risks of pacifiers should inform the policies of healthcare facilities as highlighted by the Unicef/WHO Baby-Friendly Hospital Initiative, it should be remembered that there are still controversial $^{315}$ potentially adverse effects arising from the use of pacifiers in early weaning of breastfeeding infants.

Acknowledgements We would like to acknowledge Dr Ana Cleide Valois for her suggestions, Mrs Gerlane Albuquerque for her contribution to data collection, Mrs Waldylene Calabria Barbosa for the microbiology laboratory and Mr Sergio Schechtman Sette for the database entry.

Contributors The listed authors have made the following contributions to this article: GCSS: substantial contributions to conception, design, acquisition, analysis and interpretation of data; drafting the article and revising it critically 
for important intellectual content; final approval of the version to be published. MJGdM: substantial contributions to conception, design, analysis and interpretation of data; drafting the article and revising it critically for important intellectual content; final approval of the version to be published. JBC: substantial contributions to conception, design, analysis and interpretation of data; drafting the article and revising it critically for important intellectual content; final approval of the version to be published. ISS: substantial contributions to acquisition and analysis of data; revising the article critically for important intellectual content; final approval of the version to be published. GAPdS: substantial contributions to conception, design, analysis and interpretation of data; revising the article critically for important intellectual content; final approval of the version to be published. LSdL: substantial contributions to conception, design, analysis and interpretation of data; revising the article critically for important intellectual content; final approval of the version to be published.

Funding This study was funded by the Instituto de Medicina Integral Prof Fernando Figueira-IMIP, through its institutional Fund for Education and Research.

Competing interests None.

Ethics approval Ethic approval was provided by Comite de Etica em Pesquisa em Seres Humanos do Instituto de Medicina Integral Prof. Fernando Figueira.

Provenance and peer review Not commissioned; externally peer reviewed.

Data sharing statement There are no additional data available.

\section{REFERENCES}

1. Horan TC, Gaynes RP. Surveillance of nosocomial infections. In: Mayhall CG, ed, Hospital Epidemiology and Infection Control. Philadelphia: Lippincott Williams \& Wilkins, 2004:1659-702.
2. Pittet D, Zerr DM, Posfay-Barbe KM. Infection control in paediatrics. Lancet Infect Dis 2008;8:19-31.

3. Sexton S, Natale R. Risk and benefits of pacifiers. Am Fam Physician 2009;79:681-5.

4. Tomasi E, Victoria CG, Post PR, et al. Uso de chupeta em crianças: contaminação fecal e associação com diarréia. Rev Saúde Pública 1994;28:373-9.

5. WHO Multicentre Growth Reference Study Group. Development of a WHO growth reference for school-aged children and adolescents. Bull World Health Organ 2007;85:649-732.

6. Clinical and Laboratory Standards Institute. Performance Standards for Antimicrobial Disk Susceptibility Tests; Approved Standard. Wayne: PA: NCCLS, 2003.

7. Sertório SC, Silva IA. As faces simbólica e utilitária da chupeta na visão de mães. Rev Saude Publica 2005:39:156-62.

8. Castilho SD, Rocha MAM. Uso de chupeta: história e visão multidisciplinar. J Pediatr 2009;85:480-9.

9. Curtis SJ, Jou H, Ali S, et al. A randomized controlled trial of sucrose and/or pacifier as analgesia for infants receiving venipuncture in a pediatric emergency department. BMC Pediatr 2007;7:27.

10. Araújo MFM, Ferreira $A B$, Gondim KM, et al. A prevalência de diarréia em crianças não amamentadas ou com amamentação por tempo inferior a seis meses. Cienc Cuid Saude 2007;6:76-84.

11. Novak FR, Almeida JAG, Viera GO, et al. Colostro humano: fontes naturais de probióticos? J Pediatr (Rio J) 2001;77:265-71.

12. Anon. WHO Collaborative Study Team on the role of breastfeeding on the prevention of infant mortality. Effect of breastfeeding on infant and child mortality due to infectious diseases in less developed countries: a pooled analysis. Lancet 2000;355:451-5.

13. Comina E, Marion K, Renaud FN, et al. Pacifiers: a microbial reservoir. Nurs Health Sci 2006;8:216-23.

14. Cohen E, Austin J, Welnstein M, et al. Care of children isolated for infection control: a prospective observational cohort study. Pediatrics 2008;122:411-15.

15. O'Connor NR, Tanabe KO, Siadaty MS, et al. Pacifiers and breastfeeding. Arch Pediatr Adolesc Med 2009;163:378-82. 